\title{
Predicting Los Angeles abrasion loss of rock aggregates from crushability index
}

\author{
S KAHRAMAN* and O Y TORAMAN \\ Mining Engineering Department, Nigde University, Nigde, Turkey
}

MS received 10 August 2007

\begin{abstract}
Predicting Los Angeles abrasion loss of aggregate material from some simpler tests will be useful for especially preliminary studies. For this reason, to investigate the possibility of predicting the Los Angeles abrasion loss from the crushability index, Los Angeles abrasion, crushability, density and porosity tests were performed on 11 different rock types collected from different areas of Turkey. The results of the tests were analysed using simple and multiple regression analyses. Generally significant correlations were obtained from both simple and multiple regression analyses. The correlation coefficients and estimation capabilities of the two multiple regression equations are slightly higher than that of the simple regression equation. It was concluded that the simple regression equation is practical and reliable enough for estimation purposes. However, the two multiple regression equations can be used for a more accurate estimation.
\end{abstract}

Keywords. Los Angeles abrasion loss; crushability index; porosity; density.

\section{Introduction}

Different rocks have extensively been used as an aggregate material in different construction activities such as building constructions and most public projects including roads and highways, bridges, railroad etc. Due to increasing expansion of highway and other construction activities and decreasing natural aggregate resources in the world, there is a steadily increasing market demand for crushed stone aggregates. Since 1986, the world stone production increased by $218 \%$ and it will most probably continue to grow at an even higher rate in the next decade (ISTONE 2007).

The quality of aggregates for a given usage is determined by physical and mechanical test methods. One of the important properties of rock aggregates is abrasion resistance generally tested using the Los Angeles testing machine. The abrasion resistance of aggregates is measured by the LA abrasion test originally developed to provide a quantitative method for evaluating the quality of aggregates for use in highway construction. The wear due to attrition between rock particles and also due to impact and crushing by steel spheres is measured in the test.

Although the LA abrasion test is relatively simple, it is time consuming and requires more samples compared to some direct or indirect testing methods. For this reason, some researchers have investigated the correlations between LA abrasion loss and some rock properties, and suggested some equations for the estimation of LA abrasion loss.

*Author for correspondence (sairkahraman@yahoo.com)
Kazi and Al-Mansour (1980) obtained a strong correlation between uniaxial compressive strength (UCS) determined by the Schmidt hammer and LA abrasion loss for the Saudi Arabian aggregates (volcanic and plutonic rocks) near the city of Jeddah. Ballivy and Dayre (1984) found an inverse relation between UCS and LA abrasion loss for limestones, the degree of correlation being different for different types of limestone. The porous limestones indicated strong correlation, whereas the correlation for the massive, less porous limestones varied as a function of grain size. The coarse-grained or crystalline limestones showed a higher percentage loss due to abrasion than the finegrained limestones of the same compressive strength. Cargill and Shakoor (1990) established a non-linear inverse relation between the compressive strength and LA abrasion loss divided by dry density for sedimentary and metamorphic rocks. The decrease in percentage loss with increasing strength is much more rapid at strength values below $100 \mathrm{MPa}$ than at higher strength values. Shakoor and Brown (1996) performed multivariate regression between UCS and LA loss, dry density, and absorption for carbonate rocks. They obtained a statistically significant correlation that can be used to predict UCS. Al-Harthi (2001) tested Saudi Arabian rocks and correlated LA abrasion loss with both UCS and point load index. He showed that LA abrasion loss decreases with increasing UCS and point load index. Kahraman and Gunaydin (2007) investigated the possibility of estimating the LA abrasion loss of aggregates using Schmidt hammer and point load test. They found that LA abrasion loss of aggregates can reliably be estimated from point load index. The estimation of LA 
Table 1. The location and name of the rocks sampled.

\begin{tabular}{rllcccc}
\hline \multirow{2}{*}{ Rock code } & \multicolumn{1}{c}{ Location } & \multicolumn{1}{c}{ Rock type } & $\begin{array}{c}\text { LA abrasion } \\
\text { loss (\%) }\end{array}$ & $\begin{array}{c}\text { Crushability } \\
\text { index (\%) }\end{array}$ & Density (g/cm $\left.{ }^{3}\right)$ & Porosity $(\%)$ \\
\hline 1 & Altinhisar/Nigde & Basalt & $17 \cdot 2$ & $59 \cdot 4$ & $2 \cdot 58$ & $5 \cdot 50$ \\
2 & Ortakoy/Aksaray & Granite (Anadolu grey) & $33 \cdot 7$ & $66 \cdot 3$ & $2 \cdot 55$ & $0 \cdot 62$ \\
3 & Kaman/Kirsehir & Granite(Kaman Rosa) & $40 \cdot 3$ & $86 \cdot 5$ & $2 \cdot 61$ & $0 \cdot 63$ \\
4 & Kaman/Kirsehir & Granite (Kýrcicegi) & $34 \cdot 7$ & $74 \cdot 8$ & $2 \cdot 47$ & $0 \cdot 98$ \\
5 & Uckapili/Nigde & Marble & $47 \cdot 2$ & $80 \cdot 3$ & $2 \cdot 62$ & $0 \cdot 13$ \\
6 & Iscehisar/Afyon & Marble & $40 \cdot 6$ & $80 \cdot 7$ & $2 \cdot 69$ & $0 \cdot 37$ \\
7 & Gumusler/Nigde & Migmatite & $16 \cdot 6$ & $49 \cdot 6$ & $2 \cdot 75$ & $1 \cdot 33$ \\
8 & Kilavuzkoy/Nigde & Serpentinite & $15 \cdot 9$ & $31 \cdot 5$ & $2 \cdot 73$ & $0 \cdot 91$ \\
9 & Yahyali/Kayseri & Dolomitic limestone & $25 \cdot 0$ & $54 \cdot 8$ & $2 \cdot 63$ & $0 \cdot 31$ \\
10 & Godene/Konya & Travertine & $40 \cdot 1$ & $83 \cdot 6$ & $2 \cdot 36$ & $4 \cdot 08$ \\
11 & Korkuteli/Antalya & Limestone & $28 \cdot 9$ & $77 \cdot 2$ & $2 \cdot 61$ & $0 \cdot 38$ \\
\hline
\end{tabular}

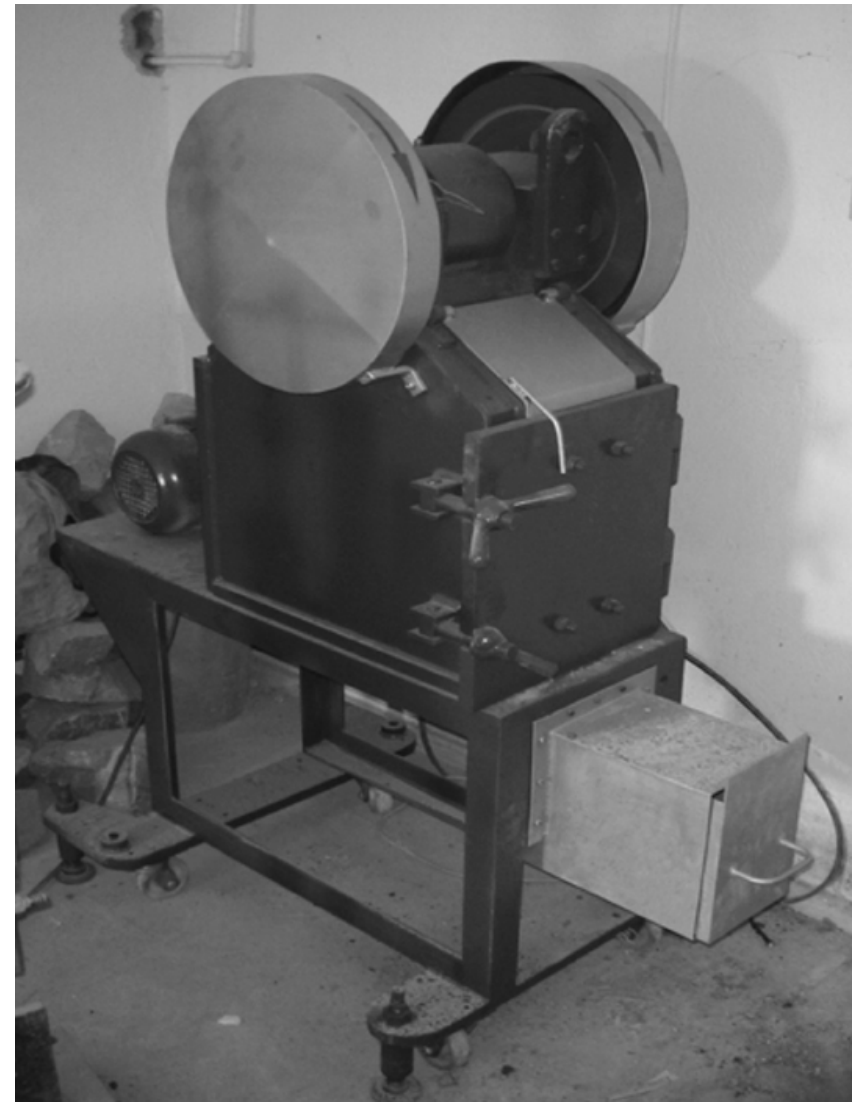

Figure 1. The jaw crusher used in the crushing tests.

abrasion loss from Schmidt hammer value is not strong as compared to point load index, however, it is in the acceptable limits. Kahraman and Fener (2007) tested 35 different rock types to investigate the relation between UCS and LA abrasion loss. They found a good correlation between LA abrasion loss and UCS. In addition, they showed that when the rocks were classified into classes according to porosity, the correlation coefficients were increased.
The main objective of this study is to investigate the possibility of estimating the LA abrasion loss of aggregates from crushability index. Crushability test requires fewer samples and less time compared to the LA abrasion test. If a strong correlation between the LA abrasion loss and crushability index is developed, this correlation will be useful for the estimation purposes especially for the preliminary studies.

\section{Sampling}

A total of eleven different metamorphic rock types were sampled, four of which were igneous, four were metamorphic and three were sedimantary. Quarries, marble factories, and natural outcrops in Nigde, Kayseri, Afyon areas of Turkey were visited and rock blocks were collected for laboratory testing. The location and name of the rocks are given in table 1.

\section{Experimental}

A total of 11 different rock types were obtained from quarries, stone processing plants, and natural outcrops in different areas of Turkey (table 1) and following tests were conducted.

\subsection{Los Angeles abrasion test}

ASTM method C 131-66 was used for the LA abrasion test. Test samples were oven-dried at $105-110^{\circ} \mathrm{C}$ for $24 \mathrm{~h}$ and then cooled to room temperature before they were tested. There are four aggregate sizes grading to choose from in the ASTM method. Grading D was used in the tests. Six steel spheres were placed in a steel drum along with $\sim 5000 \mathrm{~g}$ of aggregate sample and the drum was rotated for 500 revolutions at a rate of $30-33 \mathrm{rev} / \mathrm{min}$. After the revolution was complete, the sample was sieved through the No. 12 sieve $(1.7 \mathrm{~mm})$. The amount of material 
passing the sieve, expressed as a percentage of the original weight, was the LA abrasion loss or percentage loss.

\subsection{Crushing test}

A laboratory jaw crusher (figure 1) was used in the crushing experiments. Firstly, block samples were crushed using a hand hammer to small sizes which were suitable for the crusher and charged to the crusher with a wide outlet gap. A charging size range of 19.0-9.52 mm for the crusher was selected. The crushed samples were sieved to obtain $500 \mathrm{~g}$ samples in the selected charging size range (figure 2). After these samples were oven dried at a temperature of $110^{\circ} \mathrm{C}$ for $48 \mathrm{~h}$, they were charged to the crusher with a outlet gap of $4-8 \mathrm{~mm}$. Crushed materials were passed through the $9.525 \mathrm{~mm}$ mesh and the percentage of undersized material was described as crushability index (CI). The test was repeated two or three times for each rock type and the average value was recorded as the CI.

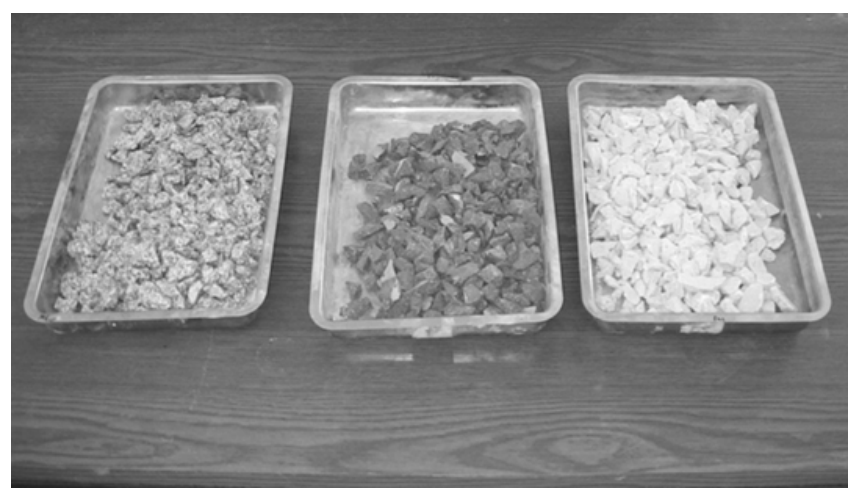

Figure 2. Some crushed rock samples in the size range of $19 \cdot 0-9 \cdot 52 \mathrm{~mm}$.

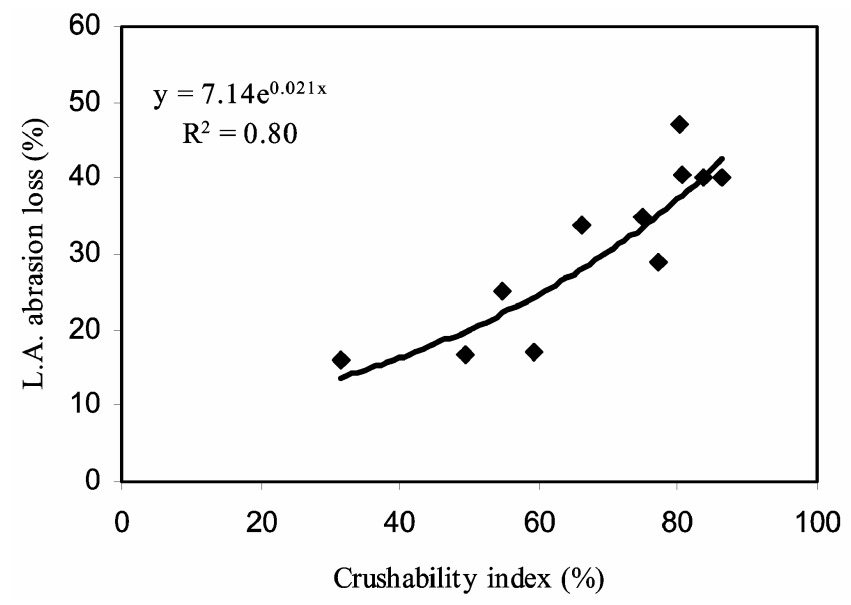

Figure 3. The correlation between LA abrasion loss and crushability index values.

\subsection{Density test}

Trimmed core samples were used in the determination of dry density. The specimen volume was calculated from an average of several calliper readings. The dry weight of the specimen was determined by a balance, capable of weighing to an accuracy of 0.01 of the sample weight. The density values were obtained from the ratio of the specimen weight to the specimen volume.

\subsection{Porosity test}

Porosity values were determined using saturation and calliper techniques. Pore volumes were calculated from dry and saturated weights and sample volumes were obtained from calliper readings. The porosity values were obtained from the ratio of the pore volume to the specimen volume.

LA abrasion loss, CI, density and porosity values of all rock types are given in table 1 .

\section{Evaluation of results}

\subsection{Simple regression analysis}

LA abrasion loss and CI values were analysed using the method of least squares regression. Linear, logarithmic, exponential and power curve fitting approximations were tried and the best approximation equation with highest correlation coefficient was determined for each regression. A strong exponential correlation between LA abrasion loss and CI values was found as shown in figure 3 . LA abrasion loss increases with increasing CI values. The equation of the curve is

$$
\mathrm{LA}=7 \cdot 14 e^{0.021 \mathrm{CI}}, \quad r^{2}=0 \cdot 80,
$$

where LA is the LA abrasion loss (\%) and CI the crushability index (\%).

\subsection{Multiple regression analysis}

Including porosity and density values, multiple linear regression analysis was performed in expectation of obtaining more stronger relations than that of the simple regression. Alternative multiple regression models are given below

$$
\begin{aligned}
& \mathrm{LA}=0.57 \mathrm{CI}+4 \gamma-18 \cdot 31, \quad r^{2}=0 \cdot 76, \\
& \mathrm{LA}=0.55 \mathrm{CI}-1 \cdot 59 n-4 \cdot 23, \quad r^{2}=0 \cdot 83, \\
& \mathrm{LA}=0.48 \mathrm{CI}-18.62 \gamma-2 \cdot 16 n+49 \cdot 68, \quad r^{2}=0 \cdot 84,
\end{aligned}
$$

where LA is the LA abrasion loss (\%), CI the crushability index $(\%), \gamma$ the density $\left(\mathrm{g} / \mathrm{cm}^{3}\right)$ and $n$ the porosity $(\%)$. 
Table 2. $t$ - and $F$-test results of the derived models.

\begin{tabular}{|c|c|c|c|c|c|c|}
\hline Equation no. & Independent variables & $t$-test & $t$-table & $F$-test & $F$-table & Correlation coefficient $\left(R^{2}\right)$ \\
\hline 1 & $\begin{array}{l}\text { Constant } \\
\text { Crushability index }\end{array}$ & $\begin{array}{l}8 \cdot 06 \\
5 \cdot 91\end{array}$ & \pm 1.81 & $34 \cdot 91$ & $5 \cdot 12$ & $0 \cdot 80$ \\
\hline 2 & $\begin{array}{l}\text { Constant } \\
\text { Crushability index } \\
\text { Density }\end{array}$ & $\begin{array}{r}-0 \cdot 32 \\
4 \cdot 35 \\
0 \cdot 20\end{array}$ & $\pm 1 \cdot 83$ & $12 \cdot 90$ & $4 \cdot 46$ & $0 \cdot 76$ \\
\hline 3 & $\begin{array}{l}\text { Constant } \\
\text { Crushability index } \\
\text { Porosity }\end{array}$ & $\begin{array}{r}-0 \cdot 62 \\
5 \cdot 84 \\
-1 \cdot 72\end{array}$ & \pm 1.86 & $19 \cdot 01$ & $4 \cdot 46$ & $0 \cdot 83$ \\
\hline 4 & $\begin{array}{l}\text { Constant } \\
\text { Crushability index } \\
\text { Density } \\
\text { Porosity }\end{array}$ & $\begin{array}{r}0 \cdot 80 \\
3 \cdot 88 \\
-0 \cdot 88 \\
-1 \cdot 89\end{array}$ & $\pm 1 \cdot 90$ & $12 \cdot 57$ & $4 \cdot 35$ & $0 \cdot 84$ \\
\hline
\end{tabular}

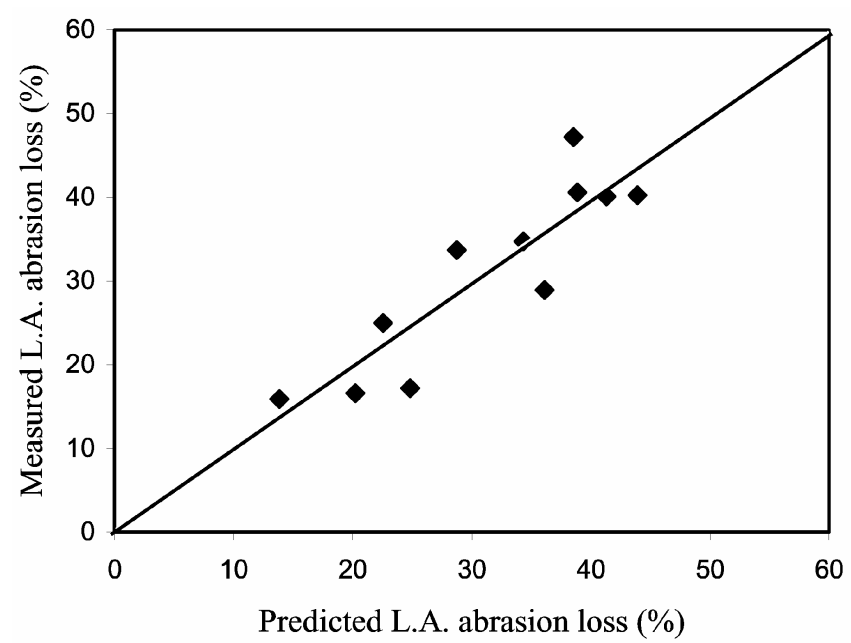

Figure 4. Predicted versus measured LA abrasion loss for (1).

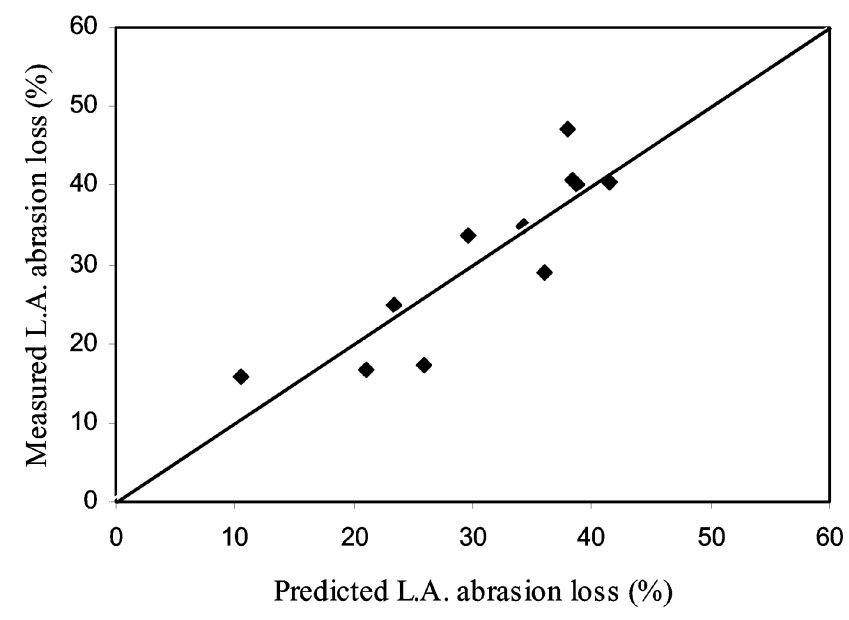

Figure 5. Predicted versus measured LA abrasion loss for (2).

\section{Validation of models derived}

Confirmation of the derived equations were done by considering correlation coefficient, the $F$-test, the $t$-test, and the plots of predicted versus observed values.

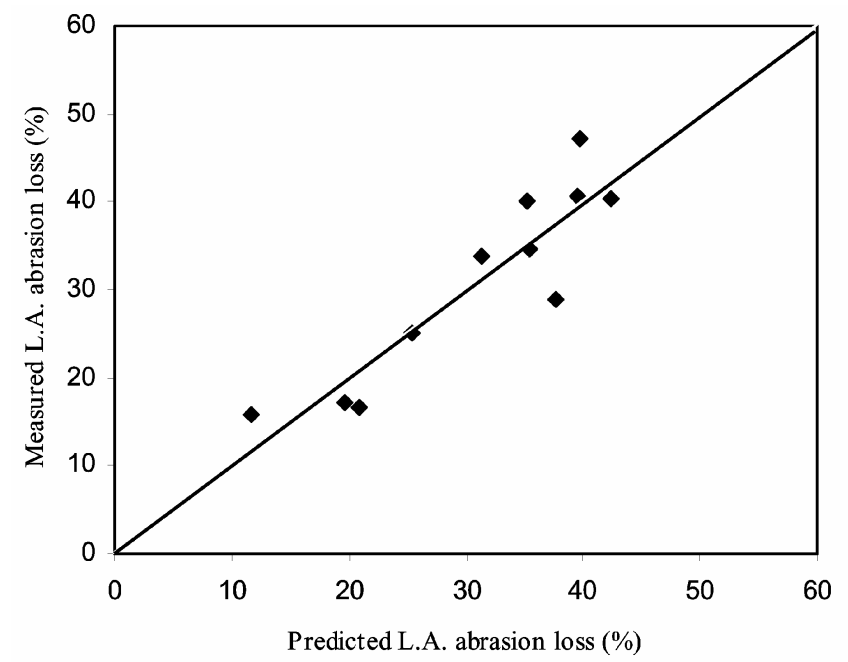

Figure 6. Predicted versus measured LA abrasion loss for (3).

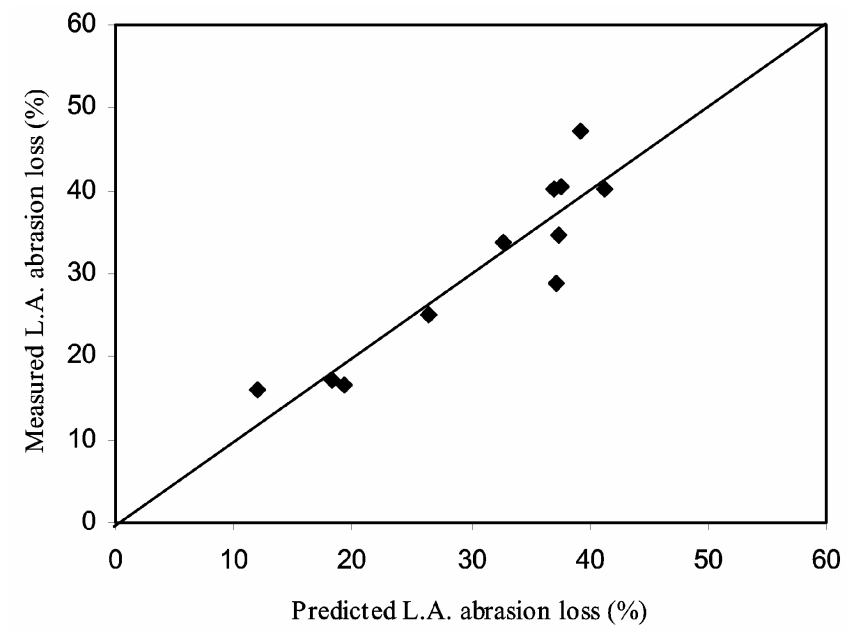

Figure 7. Predicted versus measured LA abrasion loss for (4).

The correlation coefficients $\left(R^{2}\right)$ of (1), (2), (3) and (4) are $0.80,0.76,0.83$ and 0.84 , respectively. These values are good, but they do not necessarily identify the valid model. 
The significance of $R^{2}$-values can be determined by the $t$-test, assuming that both variables are normally distributed and the observations are chosen randomly. The test compares computed $t$-value with tabulated $t$-value using the null hypothesis. In this test, a 95\% level of confidence was chosen. If the computed $t$-value is greater than tabulated $t$-value, the null hypothesis is rejected. This means that $r$ is significant. If the computed $t$-value is less than tabulated $t$-value, the null hypothesis is not rejected. In this case, $r$ is not significant. For a $95 \%$ confidence level, critical $t$-values ( $t$-table) were determined from the standard tables. It is seen in table 2 that the computed $t$-values ( $t$ test) are greater than tabulated $t$-value in (1). However, some $t$-values in (2), (3) and (4) are lower than tabulated $t$ values, indicating some doubt about the models.

To test the significance of regressions, analysis of variance was employed. In these tests, a $95 \%$ level of confidence was chosen. If the computed $F$-value ( $F$-test) is greater than tabulated $F$-value ( $F$-table), the null hypothesis is rejected and that there is a real relation between dependent and independent variables. It is shown in table 2 that the computed $F$-values are greater than tabulated $F$-values for all models. Therefore, it is concluded that the models are valid.

To see the estimation capability of the derived equations, the scatter diagrams of the observed and estimated values can be plotted. Ideally, on a plot of observed versus estimated, the points should be scattered around the $1: 1$ diagonal straight line. A point lying on the line indicates an exact estimation. A systematic deviation from this line may indicate, for example, that larger errors tend to accompany larger estimations, suggesting non-linearity in one or more variables. The graphs of estimated versus observed values in the four equations are plotted, respectively (figures 4-7). In the plots the points are generally scattered uniformly about the diagonal line, suggesting that the models are reasonable. As shown in figures 6 and 7 , the points are near to the diagonal line in (3) and (4) compared to the other plots. Although there is some doubt about (3) and (4) according to $t$-test, estimation capabilities of these equations are stronger than the other equations.

Since (1) includes one independent variable, it is more practical than the other equations. In addition, there is no doubt about its significance. Therefore, it can reliably be used for the estimation purpose. However, (3) and (4) can be used for a more accurate estimation because their estimation capabilities are stronger than the other equations.

\section{Conclusions}

To investigate the possibility of estimating the Los Angeles abrasion loss from the crushability index, the results of LA abrasion, crushability, density and porosity tests were analysed using simple and multiple regression analyses. Significant correlations were generally obtained from both simple and multiple regression analyses. Simple regression equation is practical and reliable enough for the estimation of LA abrasion loss from the crushability index. However, one who wants to make more accurate estimation can alternatively use the two multiple regression equations.

\section{References}

Al-Harthi A A 2001 Bull. Eng. Geol. Environ. 60193

Ballivy G and Dayre M 1984 Int. Assoc. Eng. Geol. Bull. 29 339

Cargill J S and Shakoor A 1990 Int. J. Rock Mech. Min. Sci. 27 495

ISTONE 2007 http://www.istone.ntua.gr/Objectives.html

Kahraman S and Fener M 2007 Mater. Letts 614861

Kahraman S and Gunaydin O 2007 Bull. Eng. Geol. Environ. 66 449

Kazi A and Al-Mansour L R 1980 Q. J. Eng. Geol. 1345

Shakoor A and Brown C I 1996 Int. Assoc. Eng. Geol. Bull. 53 98 